\title{
Seciology
}

\section{Calls for proposals}

Austrian MAB- Committee at the

Austrian Academy of Sciences

Chair: Univ.Prof.Mag.Dr. Georg Grabherr

Austrian MAB-Research : Work programme 2004/2005

\section{Call for proposals}

\section{Introduction and objectives}

According to the new research agenda for the Austrian MAB-programme (www.biosphaerenparks.at), and in response to the priorities set by the International MAB Council, the National MAB-Committee decided to focus future research predominantly on the needs of the biosphere reserves in Austria, but also to benefit from biosphere reserves as "living laboratories" for studying, testing out and demonstrating integrated management of land, water, and biodiversity. Biosphere reserves have the double mandate of nature conservation and development and rely on integrated monitoring and sustainability assessments to be developed. Both science driven and stakeholder (problem) driven research approaches are required. This was acknowledged by the Austrian MaB Committee in deciding upon the following principles for research:

1. interdisciplinarity across the ,great divide“ of natural and social sciences. All research questions should entail a focus on the interaction of natural and socioeconomic processes.

2. transdisciplinarity (,mode 2 research“). MAB research should take stakeholders perspectives seriously and communicate its research results to them. Stakeholders should have a fair chance to invoke research to help in solving their problems.

3. international orientation: Austrian $M A B$ research should be embedded into international research efforts, and use at least part of its resources for internationally comparative and or cooperative projects.

Projects should finally:

- provide a knowledge-base for defining strategies towards sustainable development in biosphere reserves

- fit particularly to the opportunities and needs of Austrian biosphere reserves

\section{Approaches and research tasks:}

The call distinguishes between two basic research types:

"Small and medium scale projects" which are comparatively short term projects (1-2 years) with a focussed research question;

Medium and long term "Integrated projects" (2-3years) which are strictly interdisciplinary; 


\section{Research topics}

\section{A. Projects for establishing basic monitoring systems (BRIM-environmental as well as social monitoring) in line with international standards}

Research questions could include:

- What is the interplay of socio-demographic dynamics and resource use?

- How do local economies (e.g. tourism, agriculture, forestry etc.) in BRs and their dynamics impact upon the environment an how could this be managed?

- How to design an internationally promising process towards a core set of BRIM indicators?

\section{B. Projects for supporting design and management of BRs}

Research questions could include:

- How can conflict resolving procedures in BRs be designed and processed? What information basis is required for this?

- How can the legal practice of Austrian BR's be improved?

- How can the Austrian pre-Sevilla type BRs be transformed to fulfil the Sevilla mandate?

- How can stakeholders involvement and ownership of the BR vision be improved?

\section{Major perspectives and development options for BRs (cross-cutting)}

Research questions could include:

- What historical transformations can be observed in BRs and how do they impact upon contemporary development options?

- Can BRs play a role in testing sustainability scenarios, such as renewable energy provision and use, or ecotourism?

\section{Call information}

Submissions can be made for small to medium size projects (maximum 2 years, <30K€) with a full proposal according to the official form (www.oeaw), or for integrated projects (2-3 years, <150k€). Proposals for integrated projects should be submitted in a 2 stage process. The pre-proposal should contain no more than 4-5 pages, but give a clear outline of the project idea, the main questions, who (project coordinator, institutions) and where; involvement of at least one biosphere reserve is essential.

\section{Procedures for small and medium size projects}

Submission of the full proposal by 21.9.2004

Proposals will be peer-reviewed by two international reviewers

Decision: Begin of December

Successful proposals will be commissioned by mid of December 2004 


\section{Procedures for integrated projects}

submission of the pre-proposal: 21.9.2004

pre-proposals will be screened and pre-selected by the MaB committee and promising preproposals will be invited for a hearing (Begin of December)

An eventual full proposal will be peer-reviewed by three international reviewers

Successful proposals will be commissioned by March 2005 


\section{Evaluation of the Research Proposal}

\section{Seccialogy}

\begin{tabular}{|c|c|c|c|}
\hline \multicolumn{2}{|l|}{ A. Formal requirements } & & \\
\hline \multicolumn{2}{|l|}{ 1. Requirements according to the program call } & achieved & $\begin{array}{c}\text { not } \\
\text { achieved }\end{array}$ \\
\hline \multicolumn{2}{|l|}{ B. Contents/Objectives } & & \\
\hline \multicolumn{2}{|l|}{ Presentation of the research problem } & & \\
\hline \multicolumn{2}{|l|}{ 1. Has the problem been described sufficiently/adequately? } & yes & no \\
\hline \multicolumn{2}{|c|}{ 2. Has the relevance of the problem been presented in a convincing manner? } & yes & no \\
\hline \multicolumn{2}{|c|}{$\begin{array}{l}\text { 3. Does the problem require the involvement of both social and natural science } \\
\text { approaches? }\end{array}$} & yes & no \\
\hline \multicolumn{4}{|l|}{ Objectives and questions } \\
\hline \multicolumn{2}{|c|}{$\begin{array}{l}\text { 4. Does it become sufficiently clear what the contribution towards resolving the } \\
\text { problem is to be? }\end{array}$} & yes & no \\
\hline \multicolumn{2}{|c|}{$\begin{array}{l}\text { 5. Do the objectives of the project correspond with the objectives of the research } \\
\text { program? }\end{array}$} & yes & no \\
\hline \multicolumn{2}{|l|}{ 6. Are the project objectives realistic/attainable? } & yes & no \\
\hline \multicolumn{4}{|l|}{ Originality } \\
\hline \multicolumn{2}{|l|}{$\begin{array}{l}\text { 7. Is the approach taken innovative/creative? } \\
\text { If so, in what way? }\end{array}$} & yes & no \\
\hline \multicolumn{4}{|l|}{ Transdisciplinarity } \\
\hline $\begin{array}{l}\text { 8. Were users involved in the wording of the objectives and } \\
\text { questions? }\end{array}$ & n.a. & yes & no \\
\hline $\begin{array}{l}\text { 9. Do the objectives and questions justify the participation of } \\
\text { external participants? }\end{array}$ & n.a. & yes & no \\
\hline $\begin{array}{l}\text { 10. Has the contribution to be made by external participants been } \\
\text { presented with sufficient clarity? }\end{array}$ & n.a. & yes & no \\
\hline 11. Do users/participants contribute to the project resources & n.a. & yes & no \\
\hline \multicolumn{4}{|l|}{ Results/Products } \\
\hline \multicolumn{2}{|l|}{ 12. Have the expected results been presented clearly? } & yes & no \\
\hline \multicolumn{2}{|c|}{ 13. Do the expected results appear to be achievable? } & yes & no \\
\hline \multicolumn{2}{|c|}{$\begin{array}{l}\text { 14. What ideas are there on how products should be developed, and are they } \\
\text { realistic? }\end{array}$} & yes & no \\
\hline
\end{tabular}




\section{Integration/Synthesis}

1. Have the methods intended for consensus building and integration been presented clearly?

2. Do the methods intended for consensus building and integration appear to be suitable to achieve the intended results and products?

\section{Scientific quality}

\section{Are the objectives of the project based upon the current state of knowledge? \\ 2. Does the research activity have internal logic? Does each step follow from the preceding one? \\ E. Transfer of knowledge and technology (concept of implementation)}

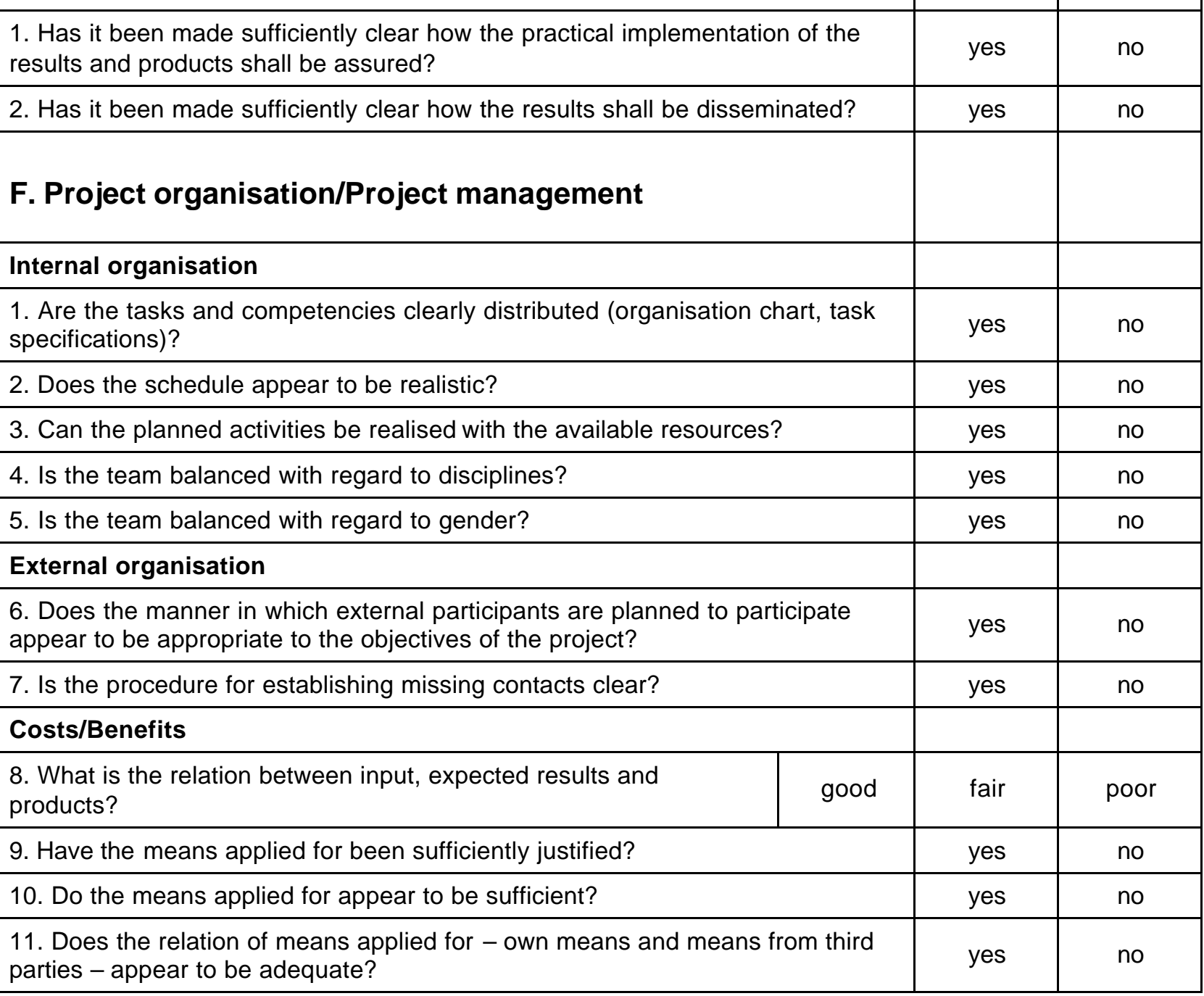




\begin{tabular}{|l|c|c|c|}
\hline G. Overall assessment & & & \\
\hline 1. What is the relevance of the project? & high & medium & low \\
\hline 2. What is the quality of the project? & high & medium & low \\
\hline 3. What is the success probability of the project? & high & medium & low \\
\hline
\end{tabular}

